\title{
ÍNDICES DE DESENVOLVIMENTO EM JUVENIS Betta splendens ALIMENTADOS COM ADITIVOS ENZIMÁTICOS
}

\author{
DEVELOPMENTAL INDEXES IN JUVENILE Betta splendens FOODS WITH \\ ENZYMATIC ADDITIVES
}

\author{
Veruska Dilyanne Silva GOMES'; Alda Lúcia de Lima AMÂNCIO²; José Jordão

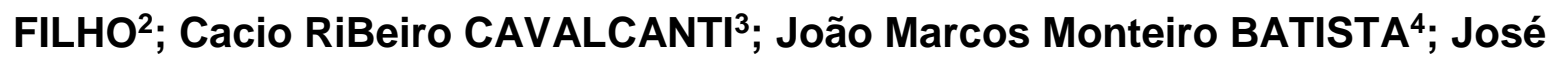 \\ Humberto Vilar da SILVA ${ }^{2}$
}

1 - Zootecnista, Dra. em Zootecnia pela Universidade Federal da Paraíba

2 - Professor(a) Dr.(a) da Universidade Federal da Paraíba, Centro de Ciências Humanas, Sociais e Agrárias (CCHSA/UFPB), campus III. Departamento de Ciência Animal - DCA.

3 - Zootecnista, Doutorando em Engenharia Agrícola. Universidade Federal de Campina Grande (UFCG).

4 - Zootecnista, Mestrando em Zootecnia. Universidade Federal da Paraíba, Centro de Ciências Agrárias (CCA), Campus II

\section{Resumo:}

A produção de peixes ornamentais vem se destacando como um dos setores mais lucrativos da piscicultura brasileira. O Betta splendens destaca-se por sua beleza, popularidade e por ser um dos peixes ornamentais mais comercializados. Neste âmbito, investir em aditivos alimentares como enzimas, pode melhorar o desempenho dos peixes. O experimento foi realizado com o objetivo de avaliar parâmetros de desempenho do peixe ornamental Betta splendens alimentado com dietas suplementadas pelas enzimas alfaamilase e protease. Foram utilizados 120 alevinos distribuídos em 5 tratamentos com 4 repetições. Os tratamentos consistiram no fornecimento de uma ração comercial farelada com $55 \%$ de proteína bruta e suplementação enzimática nas seguintes proporções: 1 Dieta referência sem suplementação com enzimas; 2 - Dieta referência + suplementação de 100 ppm de Alfa-amilase; 3 - Dieta referência + 100 ppm protease; 4 - Dieta referência +100 ppm de Alfa-amilase +200 ppm de protease; e 5 - Dieta referência +200 ppm de alfa-amilase $+400 \mathrm{ppm}$ de protease. Foram avaliados o peso, consumo de ração, conversão alimentar, comprimento, altura, largura e sobrevivência. O comprimento total $(\mathrm{mm})$ dos betas aumentou quando alimentados com as dietas 3, 4 e 5. No entanto, novos estudos devem ser realizados para comprovar a eficácia da suplementação com enzimas digestivas para a espécie.

Palavras-chaves: aquariofilia, enzimas digestivas, peixe ornamental

Abstract: Ornamental fish production has emerged as one of the most profitable sectors of Brazilian fish farming. The Betta splendens stands out for its beauty, popularity and for being one of the most commercialized ornamental fish. In this scope, investing in food additives as enzymes, can improve the performance of fish. The experiment was carried out with the objective of evaluating performance parameters of the Betta splendens ornamental fish fed diets supplemented by the alpha-amylase and protease enzymes. It was used 120 fingerlings distributed in 5 treatments with 4 replicates. The treatments consisted in the supply of a commercial meal with $55 \%$ crude protein and enzymatic supplementation in the 
following proportions: 1 - Reference diet without supplementation with enzymes; 2 Reference diet + supplementation of 100 ppm of alpha-amylase; 3 - Reference diet +100 ppm protease; 4 - Reference diet +100 ppm Alpha-amylase +200 ppm protease; and 5 Reference diet +200 ppm alpha-amylase +400 ppm protease. The weight, feed intake, feed conversion, length, height, width and survival were evaluated. The total length $(\mathrm{mm})$ of betas increased when fed diets 3, 4 and 5. However, further studies should be performed to prove the efficacy of supplementation with digestive enzymes for the species.

Keywords: aquarium fish, digestive enzymes, ornamental fish

\section{INTRODUÇÃO}

A produção de peixes ornamentais vem se destacando como um dos setores mais lucrativos da piscicultura brasileira. Esse potencial tem estimulado e impulsionado o setor, visto que, o quilo do peixe ornamental produzido pode alcançar até $500 \%$ sobre valor do quilo de peixes de corte, variando de acordo com a espécie e linhagem utilizada (BARRETO, 2017).

O peixe Betta splendens destaca-se por sua beleza, popularidade e por ser um dos peixes ornamentais mais comercializados (LIMA, 2003). É também conhecido como peixe de briga ou "Siamese fighting fish" devido ao comportamento agressivo observado principalmente nos machos em defesa do território, atacando qualquer animal intruso da mesma espécie independente do sexo, em decorrência da sua agressividade (GIANNECCHINI, 2010; SANTANA, 2001).

É um animal de origem asiática e na natureza é encontrado em pequenos lagos ou água represada, habitando ambientes aquáticos com baixo teor de oxigênio dissolvido na água (NELSON, 2006). Apresenta dimorfismo sexual acentuado, onde os machos apresentam nadadeiras bem desenvolvidas e cores intensas. As fêmeas são menores e possuem cores menos brilhantes. A espécie apresenta corpo fusiforme, com nadadeira caudal larga e arredondada. O comprimento padrão varia entre $5 \mathrm{~cm}$ a $12 \mathrm{~cm}$, dependendo da linhagem (MAURUS, 1987).

Por ser um peixe carnívoro, apresenta trato gastrointestinal curto e rápida digestão, se fazendo necessário o fornecimento de alimentação com alta biodisponibilidade de nutrientes.

Neste contexto, as enzimas exógenas podem ser uma alternativa viável na formulação de rações para a espécie, pois, segundo Guimarães et al. (2009) são aditivos alimentares eficientes na redução de fatores antinutricionais dos alimentos possibilitando aumento da digestibilidade das rações. Além de atuarem no aumento da biodisponibilidade, no intestino, de carboidratos menos complexos (MOURA et al., 2012). 
O uso destes aditivos enzimáticos forma de complexos ou blends possui maior comercialização no mercado agropecuário, visto que, as rações são formuladas com diversos ingredientes que por sua vez apresentam composição variável e necessitam de enzimas diversas para degradar seus compostos (CAMPESTRINI et al., 2005).

A inclusão de enzimas nas rações visando suplementar aquelas produzidas de forma endógena pelos peixes tem apresentado efeitos positivos em carnívoros, possibilitando maiores índices de desempenho para tucunarés (Cichla sp.) alimentados com dietas contendo protease (SOARES et al., 2008) e aumento da absorção de nutrientes das dietas suplementadas com protease e $\beta$-glutanase para truta arco-íris (DALSGAARD et. al., 2012).

Apesar da consistente representatividade dos peixes betas no cenário mundial da aquariofilia, ainda são escassas pesquisas direcionadas ao uso de aditivos alimentares. Havendo principalmente estudos em nutrição relacionados ao fornecimento de alimento vivo (CHUA et al., 2017), exigência de nutrientes como proteína bruta (ZUANON et al., 2016) e relação energia: proteína das rações sobre crescimento e composição corporal (LEMOS et al., 2014).

Mediante o exposto, o experimento foi realizado com o objetivo de avaliar parâmetros de desempenho do peixe ornamental Betta splendens alimentado com dietas suplementadas pelas enzimas alfa-amilase e protease.

\section{MATERIAL E MÉTODOS}

O experimento foi realizo no Laboratório de Aquicultura do Centro de Ciências Humanas, Sociais e Agrárias (CCHSA) da Universidade Federal da Paraíba, situado no município de Bananeiras, Paraíba - Brasil.

Foram utilizados 120 peixes betas com 30 dias de vida, estes foram obtidos a partir da reprodução de 4 casais betas comuns com 1 ano de vida, apresentando a mesma pigmentação azul escuro.

Após eclosão e absorção do vitelo, as pós-larvas foram alimentadas durante os primeiros 15 dias com alimento vivo (artêmias, microvermes e zooplâncton). Nos 15 dias que se seguiram, as pós-larvas foram adaptadas gradativamente ao consumo de ração comercial em pó com 55\% de PB, onde pela manhã era fornecido o alimento vivo e no período da tarde era fornecida a ração comercial até completarem 30 dias de vida.

Após este período os betas foram distribuídos em caixas de fibra de vidro sendo 6 
animais por unidade experimental, estocados por um período de 30 dias, com programa de iluminação de 12h/12h. A estrutura experimental consistia em um sistema de recirculação fechada de água composto por filtros mecânicos e biológicos, bomba d'água e 20 caixas de fibra de vidro. Com respiração acessória aérea, a espécie não necessita de altas concentrações de oxigênio dissolvido na água, no entanto, a bomba foi utilizada para manter a circulação da água e os parâmetros de qualidade semelhantes em todas as unidades experimentais.

O experimento foi desenvolvido em delineamento inteiramente casualizado com cinco tratamentos (Tabela 1) e quatro repetições. Os tratamentos consistiram no fornecimento de uma ração comercial farelada com 55\% de proteína bruta e suplementação enzimática nas seguintes proporções: 1 - Dieta referência sem suplementação com enzimas; 2 - Dieta referência + suplementação de 100 ppm de Alfa-amilase; 3 - Dieta referência + 100 ppm protease; 4 - Dieta referência + 100 ppm de Alfa-amilase +200 ppm de protease; e 5 - Dieta referência +200 ppm de alfa-amilase +400 ppm de protease.

TABELA 1 - Níveis de suplementação com enzimas exógenas alfa-amilase e protease nas dietas experimentais para o peixe ornamental Betta splendns.

\begin{tabular}{lccccc}
\hline Enzimas exógenas & Dieta 1 & Dieta 2 & Dieta 3 & Dieta 4 & Dieta 5 \\
\hline Alfa-amilase & 0 & 100ppm & 0 & $100 \mathrm{ppm}$ & $200 \mathrm{ppm}$ \\
Protease & 0 & 0 & $100 \mathrm{ppm}$ & $200 \mathrm{ppm}$ & $400 \mathrm{ppm}$ \\
\hline
\end{tabular}

Fonte: Arquivo pessoal

Os peixes foram alimentados às 8:00hs, $11: 30 \mathrm{hs} \mathrm{e} \mathrm{16:00hs} \mathrm{até} \mathrm{saciedade} \mathrm{aparente.}$ Todos os dias, os resíduos decantados foram retirados por meio de sifonamento e o sistema era reabastecido com água de reservatório externo.

Os parâmetros de qualidade da água foram mensurados três vezes por semana durante todo o período experimental, apresentando os seguintes valores: Temperatura de $22,7^{\circ} \mathrm{C}$ e o $\mathrm{pH}$ de 7,92 .

Ao final do experimento as sobras de ração foram quantificadas, os betas foram pesados em balança de precisão e medidos com auxílio de um paquímetro digital para a obtenção das variáveis: Peso final; ganho de peso = (peso final) -(peso inicial); consumo de ração; conversão alimentar $=$ (consumo de ração $\div$ ganho de peso); comprimento total final (medido do focinho ao final da nadadeira caudal); largura final (medida à frente do $1^{\circ}$ 
raio da nadadeira dorsal); altura final (medida à frente do $1^{\circ}$ raio da nadadeira dorsal) e sobrevivência (\%).

Os dados obtidos foram submetidos ao teste de homogeneidade, posteriormente à análise de variância e as médias foram interpretadas pelo teste de Tukey a $5 \%$ de probabilidade.

\section{RESULTADOS E DISCUSSÃO}

O experimento foi desenvolvido com alevinos machos e fêmeas, distribuídos aleatoriamente nas unidades experimentais, visto que, não foi possível realizar a sexagem do lote devido à idade e tamanho dos peixes.

James e Sampath (2004) ao avaliarem a maturidade sexual de betas juvenis a partir dos 30 dias de vida constataram que se bem nutridas, as fêmeas estavam aptas a reprodução a partir dos 90 dias. Ao final do presente experimento, os peixes betas estavam com 60 dias de vida não havendo assim influencia na utilização de lotes mistos.

A suplementação enzimática não influenciou o peso final $(\mathrm{g})$, ganho de peso $(\mathrm{g})$, consumo de ração $(\mathrm{g})$ e conversão alimentar. O peso final variou entre $0,085 \mathrm{~g}$ e 0,096g. Os betas obtiveram valores médios de ganho de peso entre 0,060 e 0,073g, o consumo de ração variou entre 0,143 e 0,178g (Tabela 2).

Signor et al. (2013), ao avaliarem a suplementação com complexo enzimático (amilase, protease, celulase, lipase, b-glucanase e fitase) em rações para o peixes ornamental japonês (Carassius auratus), não observaram diferenças significativas para o crescimento, ganho em peso e conversão alimentar.

\section{TABELA 2 - Desempenho de Betta splendens alimentados com dietas contendo enzimas digestivas.}

\begin{tabular}{lrrrrrr}
\hline Variáveis & Dieta 1 & Dieta 2 & Dieta 3 & Dieta 4 & Dieta 5 & CV(\%) \\
\hline Peso Inicial (g) & $0,0250^{\mathrm{a}}$ & $0,0251^{\mathrm{a}}$ & $0,0253^{\mathrm{a}}$ & $0,0263^{\mathrm{a}}$ & $0,261^{\mathrm{a}}$ & 3,64 \\
Peso Final (g) & $0,087^{\mathrm{a}}$ & $0,085^{\mathrm{a}}$ & $0,086^{\mathrm{a}}$ & $0,094^{\mathrm{a}}$ & $0,096^{\mathrm{a}}$ & 8,50 \\
Ganho de Peso (g) & $0,063^{\mathrm{a}}$ & $0,060^{\mathrm{a}}$ & $0,061^{\mathrm{a}}$ & $0,068^{\mathrm{a}}$ & $0,073^{\mathrm{a}}$ & 13,58 \\
Consumo de Ração (g) & $0,178^{\mathrm{a}}$ & $0,168^{\mathrm{a}}$ & $0,162^{\mathrm{a}}$ & $0,143^{\mathrm{a}}$ & $0,172^{\mathrm{a}}$ & 16,92 \\
Conversão Alimentar & $2,699^{\mathrm{a}}$ & $2,854^{\mathrm{a}}$ & $2,689^{\mathrm{a}}$ & $2,345^{\mathrm{a}}$ & $2,867^{\mathrm{a}}$ & 23,55 \\
\hline
\end{tabular}

*Médias na mesma coluna seguidas de letras distintas diferem $(P<0,05)$ pelo teste de Tukey. 
A conversão alimentar apresentou valores considerados baixos, variando entre 2,34 e 2,89 demonstrando que a espécie se mostrou eficiente em utilizar os nutrientes disponíveis na ração para a produção de tecidos, independente da adição ou não das enzimas protease e alfa-amilase.

Outras espécies de peixes ornamentais como os guppys (Poecilia reticulata) quando alimentados com dietas contendo ou não enzimas exógenas (alfa-amilase, protease e fitase) apresentaram conversão alimentar, respectivamente, 3,31 e 4,88 (Gomes et al., 2017).

O comprimento total $(\mathrm{mm})$ dos betas foi maior quando alimentados com as dietas 3 contendo $100 \mathrm{ppm}$ de protease $(19,00 \mathrm{~mm})$, com a dieta 4 contendo $100 \mathrm{ppm}$ de Alfaamilase e $200 \mathrm{ppm}$ de protease $(19,35 \mathrm{~mm})$ e com a dieta 5 suplementada com $200 \mathrm{ppm}$ de alfa-amilase e $400 \mathrm{ppm}$ de protease. No entanto, não houve diferença entre o comprimento total dos peixes que receberam a dieta 3 e os peixes que receberam as dietas 2 e 1, sendo a dieta 1 sem adição de enzimas digestivas (Tabela 3).As dietas suplementadas com protease possibilitaram maior comprimento total final nos betas, sendo possível atribuir este aumento a uma maior disponibilização de aminoácidos que foram utilizados para a produção de tecidos, pois segundo Bedford e Partridge (2011) as proteases são enzimas que atuam sobre a proteína, quebrando ligações e liberando aminoácidos prontamente disponíveis.

A mobilização de nutrientes para ganhos em comprimento total pode ser atribuída ao maior desenvolvimento das nadadeiras na espécie. Farias et al. (2006) destacam que a partir dos dois meses de vida os betas desenvolvem de forma expressiva suas nadadeiras e o dimorfismo sexual torna-se aparente.

TABELA 3 - Medidas morfométricas e sobrevivência do Betta splendens alimentados com dietas contendo enzimas digestivas.

\begin{tabular}{lcccccc}
\hline Variáveis & Dieta 1 & Dieta 2 & Dieta 3 & Dieta 4 & Dieta 5 & CV(\%) \\
\hline Comprimento Total (mm) & $18,103^{\mathrm{b}}$ & $18,073^{\mathrm{b}}$ & $19,009^{\mathrm{ab}}$ & $19,356^{\mathrm{a}}$ & $19,563^{\mathrm{a}}$ & 3,05 \\
Altura Final (mm) & $4,533^{\mathrm{a}}$ & $4,335^{\mathrm{a}}$ & $4,491^{\mathrm{a}}$ & $4,241^{\mathrm{a}}$ & $4,564^{\mathrm{a}}$ & 6,10 \\
Largura (mm) & $3,353^{\mathrm{a}}$ & $3,401^{\mathrm{a}}$ & $3,374^{\mathrm{a}}$ & $3,230^{\mathrm{a}}$ & $3,345^{\mathrm{a}}$ & 5,80 \\
Sobrevivência (\%) & $95,83^{\mathrm{a}}$ & $95,83^{\mathrm{a}}$ & $95,83^{\mathrm{a}}$ & $100,00^{\mathrm{a}}$ & $91,66^{\mathrm{a}}$ & 8,10 \\
\hline
\end{tabular}

${ }^{*}$ Médias na mesma coluna seguidas de letras distintas diferem $(\mathrm{P}<0,05)$ pelo teste de Tukey. 
A altura final $(\mathrm{mm})$ variou entre 4,53 e 4,34 $\mathrm{mm}$, a largura final $(\mathrm{mm})$ apresentou valores entre 3,23 e 3,40 mm. A sobrevivência também não foi influenciada pela inclusão das enzimas alfa-amilase e protease nas dietas.

\section{CONCLUSÃO}

A adição das enzimas exógenas alfa-amilase (100ppm) e protease (200ppm) em dietas para peixes betas influenciou positivamente o comprimento total. No entanto, novos estudos devem ser realizados para comprovar a eficácia da suplementação com enzimas digestivas para a espécie.

\section{REFERENCIAS}

BARRETO, L. M. Aquicultura ornamental de água doce - Parte I. Aquicultura brasil, v.8, p. $14-18,2017$.

BEDFORD, M. R.; PARTRIDGE, G. G. Enzymes in farm animal nutrition. 2. ed. London: CAB Internationa, 2011.

CAMPESTRINI, E.; SILVA, V.T.M.; APPELT, M.D. Utilização de enzimas na alimentação animal. Revista Eletrônica Nutritime, v. 2, n. 6, p. 259-272, 2005.

CHUA, K. V.; SH, T.; LIEW, J. Y.; HASNITA, C. H. Fruit Fly Maggots as Alternative Feed to Improve Siamese Fighting Fish (Betta splendens) Fecundity, Eggs Hatchability and Fry Survivability. Journal of Tropical Resources and Sustainable Science, v. 5, p. 51-54, 2017.

DALSGAARDA, J.; VERLHACB, V.; HJERMITSLEVC, N. H.; EKMANNC, K. S.; FISCHERD, M.; KLAUSEND, M.; PEDERSENA, P. B. Effects of exogenous enzymes on apparent nutrient digestibility in rainbow trout (Oncorhynchus mykiss) fed diets with high inclusion of plant-based protein. Animal Feed Science and Technology. Vol. 171, p. 181- 191. 2012.

FARIA, P.M.C.; CREPALDI, D. V.; TEIXEIRA, E. A.; RIBEIRO, L. P.; SOUZA, A. B.; CARVALHO, D. C.; MELO, D. C.; SALIBA, E. O. S. Criação, manejo e reprodução do peixe Betta splendens (Regan 1910). Revista Brasileira de Reprodução Animal, Belo 
Horizonte, v.30, n.3/4, p.134-149, jul./dez. 2006.

GIANNECCHINI, L.G. Fotoperíodo na reprodução de Betta splendens. (dissertação) Jaboticabal. 30p. 2010.

GOMES, V. D. S.; SILVA, J. H. V.; CAVALCANTI, C. R.; LIMA, M. C.; JORDÃO FILHO, J.; AMÂNCIO, A. L. L. Enzimas exógenas na alimentação do peixe guppy (Poecilia reticulata). Archives of Veterinary Science. v.22, n.3, p.24-29, 2017.

GUIMARÃES, I.G.; FALCON, D. R.; SCHICH, D.; BARROS, M. M.; PEZZATO, L. E. Digestibilidade aparente de rações contendo complexo enzimático para tilápia-do-nilo. Arquivos Brasileiros de Medicina Veterinária e Zootecnia, v.61, n.6, p.1397-1402, 2009.

JAMES R, SAMPATH K. Effect of different feeds on growth and fecundity in ornamental fish, Betta splendens (Regan). Indian Journal Fish, v.49, p.279-285, 2002.

LEMOS, M. V. A. D., ARANTES, T. Q., SOUTO, C. N., MARTINS, G. P., ARAÚJO, J. G., \& GUIMARÃES, I. G. Effects of digestible protein to energy ratios on growth and carcass chemical composition of siamese fighting fish (Betta splendens). Ciência e Agrotecnologia, v. 38, n. 1, p. 76-84, 2014.

LIMA, A. O. Aquicultura ornamental: O potencial de mercado para algumas espécies ornamentais: Formas alternativas de diversificação da produção na aquicultura brasileira. Revista Panorama da Aquicultura, v. 13, p. 23-29, 2003.

MAURUS, W. Bettas a complete introduction. New jersey-USA: t.f.h., 128p. 1987.

MOURA, G.S.; LANNA, E.A.T.; FILER, K.; FALKOSKI, D.L.; DONZELE, J. L.; OLIVEIRA, M.G.A.; REZENDE, S.T. Effects of enzyme complex SSF (solid state fermentation) in pellet diets for Nile tilapia. Revista Brasileira de Zootecnia. v.41, n.10, p.2139-2143, 2012.

NELSON, J.S. Fishes of the world. 4 ed. Canada: John Wiley \& Sons, Inc. 601p. 2006. SANTANA, E.W.P; PAMPLONA, L.G.C; OLIVEIRA-LIMA, J.W; RIBEIRO, Z.M \& REGAZZI, A.C.F. Biological Control of Aedes aegypti I. Evaluation of the larvivorous potential of the 
Betta splendens in water boxes in Fortaleza, Ceará, Brasil. In: Resumos do XXXVII Congresso da Sociedade Brasileira de Medicina Tropical p. 37, 2001.

SIGNOR, A.A.; LUCHESI, J.D.; COSTA, J.M.; FRIES, E.M.; ALTEVIR SIGNOR, A.; FEIDEN, A.; BOSCOLO, W.R. Complexo enzimático na dieta de alevinos de kinguio (Carassius auratus). Semina: Ciências Agrárias, Londrina, v. 34, n. 3, p. 1381-1388, 2013.

SOARES, E.C.; PEREIRA FILHO, M.; ROUBACH, R.; SILVA, R.C.S. Protease exógena em dietas para juvenis de tucunaré-paca (Cichla sp.). Revista Brasileira de Zootecia, v.37, n.6, p.971-976, 2008.

ZUANON, J. A. S., Morais, J. A., \& Souza, A. P. Dietary crude protein levels for juvenile beta. Boletim do Instituto de Pesca, São Paulo, v. 42, n. 3, p. 590-597, 2016. 